\title{
Control of PHAS-I phosphorylation in 3T3-L1 adipocytes: effects of inhibiting protein phosphatases and the p70 $0^{56 \mathrm{~K}}$ signalling pathway
}

\author{
T.-A . L in, J . C. L awrence, J r. \\ Department of Molecular Biology and Pharmacology, Washington University School of Medicine, St. Louis, Missouri, USA
}

Summary PHAS-I is a recently discovered regulator of translation initiation. Non-phosphorylated PHASI binds and inhibits eukaryotic initiation factor-4E, the mRNA cap-binding protein that mediates a ratelimiting step in translation initiation. When PHAS-I is phosphorylated in response to insulin, the PHASI/eukaryotic initiation factor-4E complex dissociates. The present study was conducted to investigate mechanisms involved in the control of PHAS-I. Phosphorylation of PHAS-I was monitored by immunoblotting after subjecting extracts to polyacrylamide gel electrophoresis in the presence of sodium dodecyl sulphate. This was possible because phosphorylation markedly decreases the electrophoretic mobility of PHAS-I. Incubating 3T3-L1 adipocytes with rapamycin and wortmannin inhibited insulin-stimulated phosphorylation of PHAS-I at concentrations similar to those that inhibited activation of $\mathrm{p} 70^{\mathrm{S} 6 \mathrm{~K}}$. Both agents increased the amount of PHAS-I that co-purified with eukaryotic initiation factor-4E when extracts were fractionated using a cap affinity resin, indicating that PHAS-I binding to the initiation factor was increased. Incubating adipocytes with the protein phosphatase inhibitors, calyculin A and okadaic acid, increased PHAS-I phosphorylation and opposed the effects of rapamycin on decreasing PHAS-I phosphorylation. However, neither okadaic acid nor calyculin A abolished the effects of rapamycin on PHAS-I. These results suggest that the phosphorylation of PHAS-I in response to insulin occurs via the $\mathrm{p} 70^{\mathrm{S} 6 \mathrm{~K}}$ signalling pathway. By regulating eukaryotic initiation factor-4E, PHAS-I may have important roles in the control of both protein synthesis and mitogenesis. [Diabetologia (1997) 40: S18-S24]

Keywords Insulin, rapamycin, wortmannin, calyculin A, okadaic acid, mRNA translation.
Insulin is of vital importance in the control of protein metabolism, as dramatically exemplified by the severe muscle wasting that occurs with insulin

Corresponding author: Dr. J. C. Lawrence, Jr., Department of Pharmacology, Health Sciences Center, Box 448, University of Virginia School of Medicine, Charlottesville, VA 22908, USA

Abbreviations: eIF, Eukaryotic initiation factor; FKBP12, FK506 binding protein of $\mathrm{M}_{\mathrm{r}}=12000$; HEPES, N-(2-hydroxyethyl)piperazine- $\mathrm{N}^{\prime}$-(2-ethanesulfonic acid); MAP kinase, mitogen-activated protein kinase; $\mathrm{m}^{7} \mathrm{GPPPN}$, mRNA cap which consists of 7-methylguanosine linked via a triphosphate unit to the 5 '-hydroxyl of the first nucleotide $(\mathrm{N})$ in the mRNA; mTOR, mammalian target of rapamycin; PI 3 kinase, phosphatidyl inositol $3^{\prime} \mathrm{OH}$ kinase; $\mathrm{p} 70^{\mathrm{S} 6 \mathrm{~K}}$, ribosomal protein S6 kinase of apparent $\mathrm{M}_{\mathrm{r}}=70000$. deficiency in untreated diabetes mellitus [1]. Insulin stimulates protein synthesis in skeletal and cardiac muscle cells, hepatocytes, and adipocytes by complex regulatory mechanisms involving both transcriptional and translational processes $[1,2]$. At the transcriptional level, messages encoding many proteins and enzymes involved in the insulin response are synthesized at an increased rate. At the translational level, mRNA is translated more rapidly, resulting in a generalized increase in protein synthesis. In addition, the rates of translation of certain classes of mRNAs are increased much more than the overall rate of translation [3, 4]. Examples are messages containing structured (G/C-rich) $5^{\prime}$ non-translated regions [5], and messages having a polypyrimidine motif near the $5^{\prime}$ end [6], as is found in mRNAs 
encoding ribosomal subunits. Indeed, the rapid synthesis of ribosomal proteins serves to gear the cell up for making protein $[3,4]$.

Because many minutes to hours are required for newly synthesized proteins to accumulate in response to insulin, the effects of insulin on protein synthesis have been viewed as 'long-term' effects and have been distinguished from the acute actions of insulin involved in the regulation of carbohydrate and lipid metabolism. There has been a tendency to assume that the transduction pathways involved in controlling protein synthesis must differ from those involved in the acute responses. However, this is based on a misperception as initial events involved in the stimulation of protein synthesis by insulin occur rapidly. Indeed, there is increasing evidence that protein synthesis is controlled by transduction elements that are also involved in the regulation of carbohydrate and lipid metabolism [7].

Insulin activates multiple Ser/Thr protein kinases, resulting in rapid increases in the phosphorylation of many proteins $[8,9]$. One such protein is a heat- and acid-stable species of apparent $\mathrm{M}_{r}=22000$ [8, 9], designated PHAS-I [10]. cDNA encoding PHAS-I was recently cloned [10] and the protein was found to represent the first member of a family of translational regulators that interact with eIF-4E [11-14], the mRNA cap-binding protein [15-17]. The mRNA cap is an $\mathrm{m}^{7}$ GPPPN (where $\mathrm{N}$ is any nucleotide) motif found at the 5' end of eukaryotic mRNA [18]. The cap is essential for translation initiation mediated by the initiation complex, eIF-4F, which is formed by the following three subunits: eIF-4E, eIF-4A, and p220 [15-17]. eIF-4A is an ATP-dependent helicase which is involved in melting of secondary structure in the $5^{\prime}$ non-translated region of $\mathrm{mRNA}$, allowing for more efficient translation of messages having structured $5^{\prime}$ non-translated regions. p220 is a relatively large protein (apparent $M_{r} \sim 220000$ ) that binds to both eIF-4E and eIF-4A. eIF-4E is the least abundant of the subunits, and its activity appears to be rate-limiting for translation initiation $[15,17]$. As initiation is generally the limiting phase for mRNA translation [16], eIF-4E is an important control point for protein synthesis.

Non-phosphorylated PHAS-I binds to eIF-4E and inhibits translation of capped mRNA, both in cells and in in vitro translation systems [14, 19]. When phosphorylated in response to insulin, PHAS-I dissociates from eIF-4E $[12-14,19]$. As eIF-4E appears to be limiting for eIF-4F activity, the release of eIF-4E from PHAS-I in response to insulin provides a potential explanation for the increase in eIF-4F activity [20]. Increasing eIF-4F activity, via the mRNA helicase of eIF-4A, is the likely explanation for the selective increase in translation of messages, such as ornithine decarboxylase mRNA [5], that have G/C-rich 5 ' non-translated domains.
PHAS-I is an excellent substrate for mitogen activated protein (MAP) kinase [21], and when phosphorylated by MAP kinase, PHAS-I is no longer able to bind eIF-4E in vitro [13]. Insulin activates MAP kinase and promotes phosphorylation of PHAS-I in the major site phosphorylated by MAP kinase in vitro [21], suggesting that MAP kinase is involved in the control of PHAS-I in cells. However, the role of MAP kinase in mediating the response to insulin is still unclear, as inhibiting activation of the kinase with an inhibitor of MAP kinase did not block the phosphorylation of PHAS-I in response to insulin [12]. Moreover, we have recently shown that rapamycin inhibits PHAS-I phosphorylation under conditions in which MAP kinase activity is not decreased [12]. Sensitivity to rapamycin is generally viewed as indicative of the $\mathrm{p} 70^{\mathrm{S} 6 \mathrm{~K}}$ pathway, as rapamycin blocks activation of the kinase by insulin and growth factors [22-24]. Purified $\mathrm{p} 70^{\mathrm{S} 6 \mathrm{~K}}$ did not directly phosphorylate recombinant PHAS-I [21], indicating that $\mathrm{p} 70^{\mathrm{S} 6 \mathrm{~K}}$, itself, is not responsible for phosphorylating PHAS-I in cells. However, other elements in the $\mathrm{p} 70^{\mathrm{S} 6 \mathrm{~K}}$ pathway would seem to be good candidates. In principle, rapamycin could act either by inhibiting a kinase that phosphorylates both $\mathrm{p} 70^{\mathrm{S} 6 \mathrm{~K}}$ and PHAS-I, or by stimulating a protein phosphatase. In this report we describe experiments that were performed to investigate further the control of PHAS-I phosphorylation by the rapamycin-sensitive pathway.

\section{Materials and methods}

Cell culture. 3T3-L1 fibroblasts were cultured in Dulbecco's Modified Eagle's Medium containing 10\% fetal calf serum on plastic culture dishes $(10 \mathrm{~cm}$ diameter $)$ and converted to adipocytes by using differentiation medium as described previously [25]. Experiments were performed on adipocytes 1216 days after withdrawal from differentiation medium. Before incubations with insulin or other agents, the growth medium was replaced with buffer containing (in mmol/l) $135 \mathrm{NaCl}$, $5.4 \mathrm{KCl}, 1.4 \mathrm{CaCl}_{2}, 1.4 \mathrm{MgSO}_{4}, 5$ glucose, 0.07 bovine serum albumin, 0.2 sodium phosphate and 10 HEPES, pH 7.4. After incubating for $3 \mathrm{~h}$, this buffer was replaced with buffer containing no additions or buffer containing either rapamycin (Calbiochem-Novabiochem, San Diego, Calif., USA) or wortmannin (Sigma Chemical Co., St. Louis, Mo., USA). After incubating for $10 \mathrm{~min}$, insulin (Eli Lilly Co, Indianapolis, Ind., USA) or the protein phosphatase inhibitors [26] (LC Laboratories, Woburn, Mass., USA), okadaic acid or calyculin A, were added and the incubations were continued for the times indicated. To terminate the incubation, the buffer was aspirated and the cells were rinsed once with $4{ }^{\circ} \mathrm{C}$ phosphatebuffered saline and homogenized ( $1 \mathrm{ml}$ buffer per dish) in a glass homogenization tube with a Teflon pestle driven at 1000 rev/min. The homogenization buffer contained $1 \mathrm{mmol} / 1$ EDTA, $5 \mathrm{mmol} / \mathrm{l} \mathrm{EGTA,} 10 \mathrm{mmol} / 1 \mathrm{MgCl}_{2}, 2 \mathrm{mmol} / \mathrm{l}$ dithiothreitol, $0.1 \mathrm{mmol} / \mathrm{l}$ phenylmethylsulfonyl fluoride, $10 \mathrm{mg} / \mathrm{l}$ leupeptin, $10 \mathrm{mg} / \mathrm{l}$ aprotinin, $1 \mathrm{mmol} / \mathrm{l}$ benzamidine, $10 \mathrm{mmol} /$ 1 potassium phosphate, and $50 \mathrm{mmol} / \mathrm{l} \beta$-glycerophosphate $(\mathrm{pH}$ 7.3). Homogenates were centrifuged at $10000 \times \mathrm{g}$ for 
$20 \mathrm{~min}$, and the supernatants were retained for analyses. The protein content was determined by using bicinchoninic acid [27]. Ribosomal protein S6 kinase activity was measured using intact $40 \mathrm{~S}$ ribosomes as substrate as described previously [12].

D etection of PHAS-I by immunoblotting. PHAS-I antiserum was generated by immunizing rabbits with $\left[\mathrm{H}^{6}\right]$ PHAS-I [21]. eIF-4E antibodies were generated by immunizing rabbits with a peptide (CTATKSGSTTKNRFV) having a sequence derived from the $\mathrm{COOH}$-terminal region of mouse eIF-4E. Prior to injection, the peptide was conjugated to keyhole limpet haemocyanin. The antibodies were affinity-purified by using a column prepared with the peptide, which was coupled to a resin (10 $\mathrm{g}$ of peptide/l of resin) by using Sulfolink reagent as directed by the supplier (Pierce, Rockford, Ill., USA). Samples of extracts were subjected to SDS-PAGE using the method of Laemmli [28]. Proteins were electrophoretically transferred to nylon membranes (Immobilon, Millipore, Milford, Mass., USA), which were immersed in phosphate-buffered saline containing $5 \%$ powdered milk (Carnation) and incubated for at least $1 \mathrm{~h}$. Sheets were then incubated with PHAS-I antiserum (1000-fold diluted) or eIF-4E antibodies $(1 \mathrm{mg} / \mathrm{l})$ in phosphate-buffered saline plus milk for $2 \mathrm{~h}$, then washed as described previously [13]. Antibody binding was detected by enhanced chemiluminescence (Tropix system, Bedford, Mass., USA) using alkaline phosphatase conjugated to goat anti-rabbit IgG. The intensities of the bands corresponding to PHAS-I were determined by two-dimensional scanning using a laser densitometer (Molecular Dynamics, Sunnyvale, Calif., USA).

PHAS-I and elF-4E complexes. The association of PHAS-I and eIF-4E was assessed by determining how much PHAS-I was recovered when eIF-4E was purified with $\mathrm{m}^{7} \mathrm{GTP}-\mathrm{Seph}-$ arose [13]. For affinity purification of PHAS-I/eIF-4E, $\mathrm{m}^{7}$ GTP-Sepharose (Pharmacia Biotech Inc, Piscataway, N. J., USA) was incubated with extract and washed as described previously [13]. Proteins were eluted with SDS-sample buffer and subjected to SDS-PAGE. PHAS-I and eIF-4E were detected by immunoblotting.

\section{Results}

Dephosphorylation of PHAS-I in response to rapamycin and wortmannin. When subjected to one dimensional PAGE in the presence of SDS, PHAS-I from 3T3-L1 adipocytes is resolved into three bands $[12,13]$, designated $\alpha, \beta$, and $\gamma$ (Fig. 1). Phosphorylation of the appropriate sites retards the electrophoretic mobility of PHAS-I [12, 13, 21]. The $\alpha$ form has been shown to represent non-phosphorylated PHAS-I [12]. $\beta$ and $\gamma$ represent forms of PHAS-I containing increasing amounts of covalently bound phosphate [12]. Thus, changes in the relative amounts of the three electrophoretic forms of PHAS-I are indicative of changes in the phosphorylation state of the protein.

Insulin-stimulated phosphorylation of PHAS-I results in a decrease in the amount of PHAS-I $\alpha$ and an increase in the most highly phosphorylated form, PHAS-I $\gamma$ (Fig.1). As previously reported

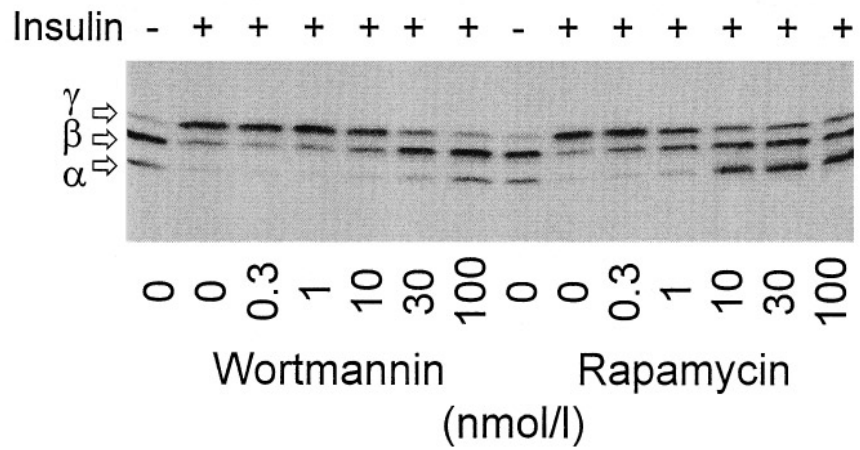

Fig. 1. Effects of insulin and increasing concentrations of wortmannin or rapamycin on the electrophoretic mobility PHAS-I. 3T3-L1 adipocytes were incubated at $37^{\circ} \mathrm{C}$ with increasing concentrations of rapamycin or wortmannin for $10 \mathrm{~min}$. Insulin ( $20 \mathrm{nmol} / \mathrm{l}$ final) was added as indicated, and incubations were continued for $10 \mathrm{~min}$. Samples of extracts $(20 \mu \mathrm{l})$ were dissolved in SDS sample buffer and subjected to SDS-PAGE. A representative immunoblot showing $\operatorname{PHAS}-\mathrm{I} \alpha, \beta$ and $\gamma$ is presented
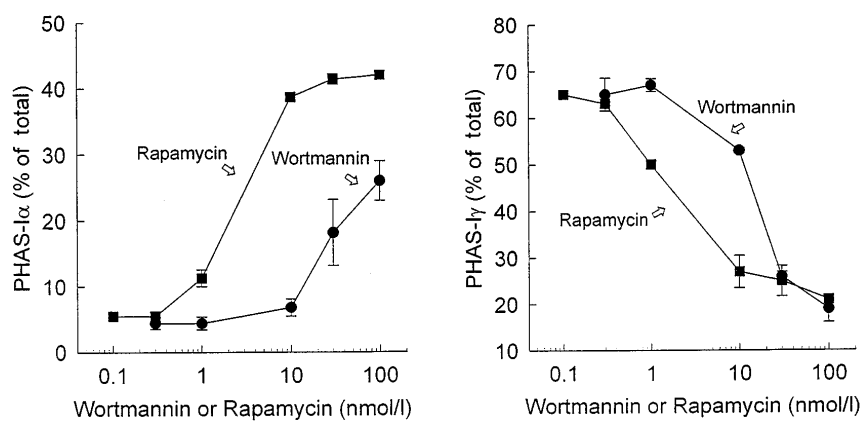

Fig. 2. Effects of increasing concentrations of wortmannin and rapamycin on the amounts of PHAS-I $\alpha$ and PHAS-I $\gamma$. Experiments were conducted as described in the legend to Figure 1. Relative amounts of the different electrophoretic forms of PHAS-I were determined from the optical densities of the appropriate bands, which were measured by scanning laser densitometry. PHAS-I $\alpha$ (left) and PHAS-I $\gamma$ (right) are expressed as percentages of the total amount of PHAS-I, and are mean values \pm half the range of two experiments. The values for the $\alpha$ and $\gamma$ forms in insulin-treated cells incubated without wortmannin or rapamycin were $7.1 \pm 1.1$ and $64.4 \pm 3.3$, respectively

[12], rapamycin attenuates the effect of insulin (Fig.1). The half-maximum effects of rapamycin on increasing PHAS-I $\alpha$ (Fig. 2), the form that binds most tightly to eIF-4E, and on decreasing PHAS-I $\gamma$ were observed with concentrations of 3 and $2 \mathrm{nmol} /$ 1 , respectively. These concentrations were 3 to 4 times higher than that needed to half-maximally inhibit the activation of ribosomal protein S6 kinases by insulin (Fig. 3).

The activation of $\mathrm{p} 70^{\mathrm{S} 6 \mathrm{~K}}$ by insulin is potently inhibited by the phosphatidyl inositol $3{ }^{\prime} \mathrm{OH}$ kinase (PI 3 kinase) inhibitor, wortmannin [22, 29]. Wortmannin mimicked rapamycin by inhibiting the effects of insulin on PHAS-I phosphorylation (Fig.1). 


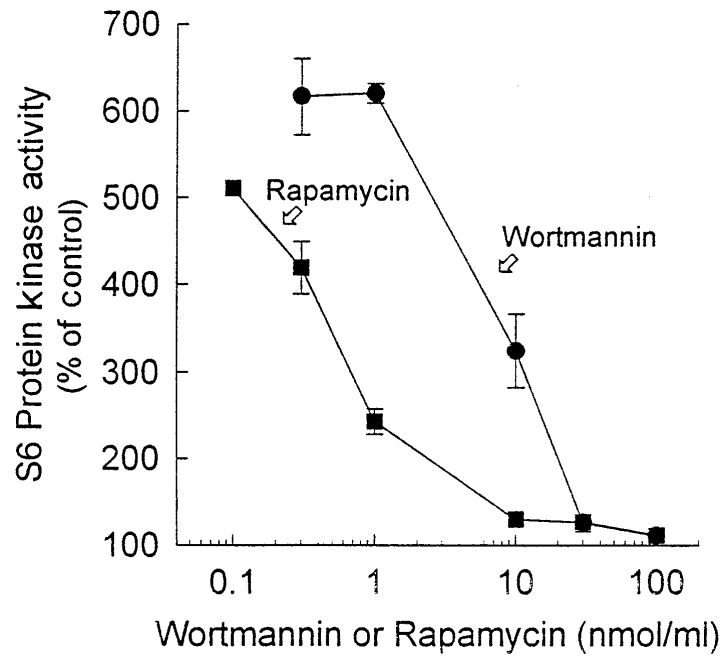

Fig. 3. Effect of increasing concentrations of wortmannin and rapamycin on ribosomal protein S6 kinase activity. Cells were incubated with wortmannin, rapamycin and insulin as described in the legend to Figure 1. The activity of S6 protein kinases was measured using intact $40 \mathrm{~S}$ ribosomes as substrate. The results are expressed as percentages of the control value and are means \pm half the range from two experiments. The value for insulin-treated cells incubated without rapamycin or wortmannin was $616 \pm 44$

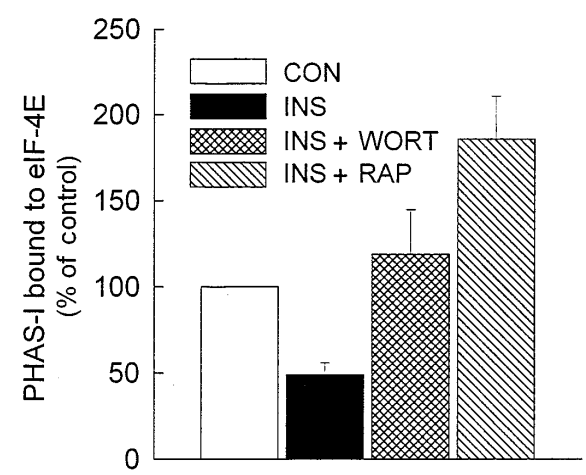

Fig. 4. Rapamycin and wortmannin increase binding of PHASI to eIF-4E. 3T3-L1 adipocytes were incubated at $37^{\circ} \mathrm{C}$ without additions (CON) or with $100 \mathrm{nmol} / \mathrm{l}$ wortmannin (WORT) or $30 \mathrm{nmol} / \mathrm{l}$ rapamycin (RAP) for $10 \mathrm{~min}$. Incubations were continued without or with $20 \mathrm{nmol} / 1$ insulin (INS) for $10 \mathrm{~min}$. Extracts were prepared and eIF-4E was partially purified by using $\mathrm{m}^{7}$ GTP-Sepharose. Samples were subjected to SDSPAGE and the amounts of PHAS-I that co-purified with eIF$4 \mathrm{E}$ were determined by immunoblotting. The results are expressed relative to control and are mean values + half the range of two experiments

As with rapamycin, approximately 3 - to 4-fold higher concentrations of wortmannin were required to inhibit PHAS-I phosphorylation in response to insulin (Fig. 2) than to inhibit activation of ribosomal protein S6 kinases by the hormone (Fig. 3). Incubating cells with rapamycin or wortmannin increased the amount of PHAS-I that was recovered when eIF-4E was partially purified by using $\mathrm{m}^{7} \mathrm{GTP}-\mathrm{Seph}-$ arose (Fig. 4).

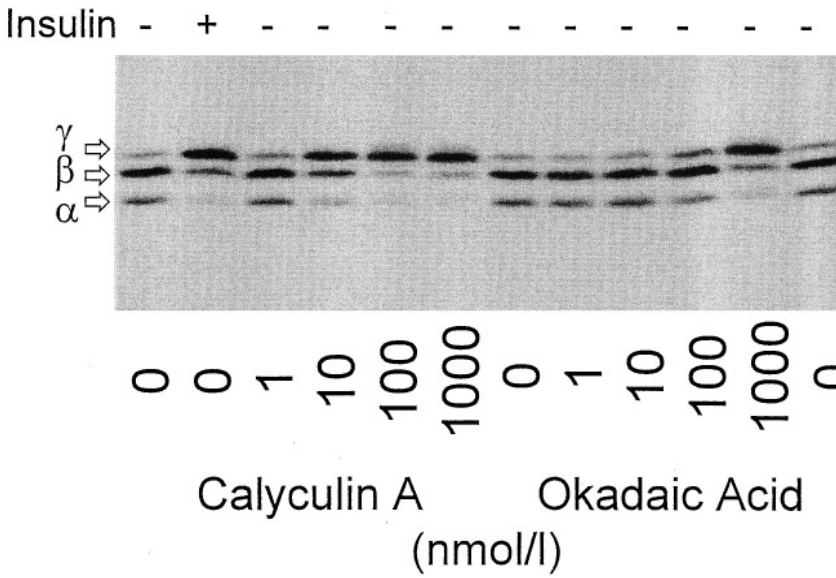

Fig. 5. Increased phosphorylation of PHAS-I in response to the protein phosphatase inhibitors, calyculin A and okadaic acid. 3T3-L1 adipocytes were incubated at $37^{\circ} \mathrm{C}$ without additions, with $20 \mathrm{nmol} / \mathrm{l}$ insulin, or with increasing concentrations of calyculin A and okadaic acid for 20 min. A PHAS-I immunoblot from a representative experiment is presented
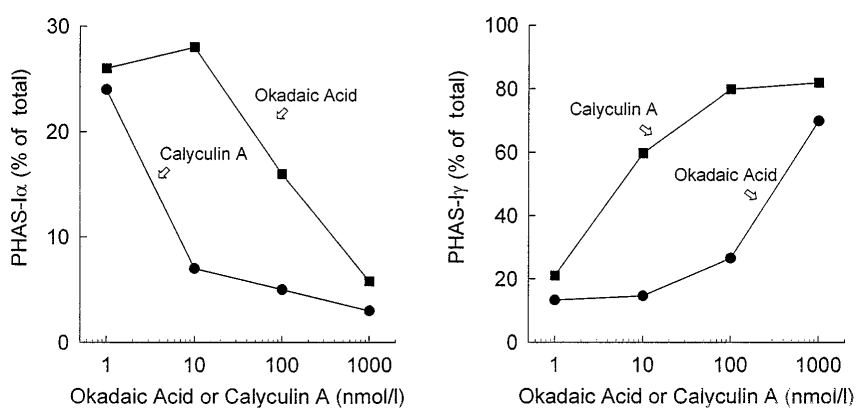

Fig. 6. Effects of increasing concentrations of calyculin $A$ and okadaic acid on the relative amounts of PHAS-I $\alpha$ and PHASI $\gamma$. Cells were incubated as described in the legend to Fig. 5. Relative amounts of the different electrophoretic forms of PHAS-I were determined by optical density scanning. Results for the $\alpha$ (left) and $\gamma$ (right) forms of PHAS-I are expressed as percentages of the total PHAS-I and are mean values from a representative experiment

Protein phosphatase inhibition. In contrast to rapamycin and wortmannin, the protein phosphatase inhibitors [26], calyculin A and okadaic acid, decreased the electrophoretic mobility of PHAS-I (Fig. 5). The maximum effects of the inhibitors on increasing PHAS-I phosphorylation were similar to those of insulin; however, calyculin A was approximately 100 times more potent than okadaic acid in decreasing PHAS-I $\alpha$ and in increasing PHAS-I $\gamma$ (Fig. 6). To investigate possible interactions between rapamycin and the phosphatase inhibitors, cells were incubated with combinations of maximally effective concentrations of the agents. With the combinations of rapamycin plus either insulin, calyculin A or okadaic acid, the levels of PHAS-I $\alpha$ and PHAS-I $\gamma$ observed were intermediate to the levels observed when cells were incubated with rapamycin and the respective agents individually (Fig. 7). 

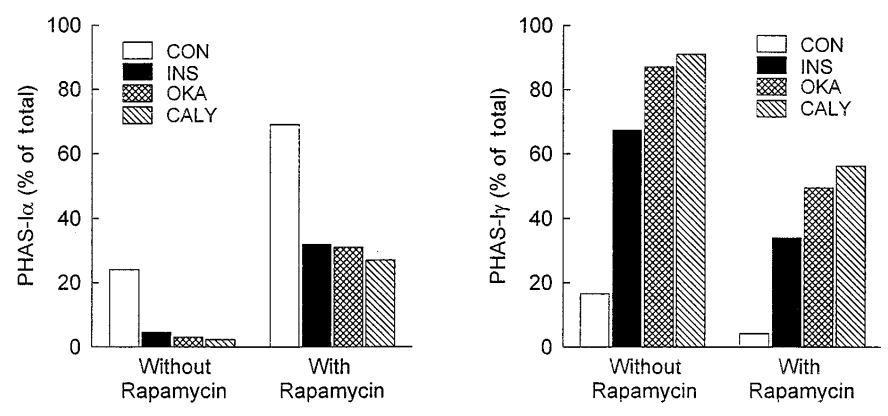

Fig. 7. Effect of phosphatase inhibitors in the absence and presence of rapamycin on PHAS-I $\alpha$ and PHAS-I $\gamma$. 3T3-L1 adipocytes were incubated at $37^{\circ} \mathrm{C}$ without additions $(\mathrm{CON})$ or with $20 \mathrm{nmol} / \mathrm{l} \mathrm{rapamycin}$ for $10 \mathrm{~min}$. The cells were then incubated with the same concentrations of rapamycin with or without either $20 \mathrm{nmol} / \mathrm{l}$ insulin (INS), $1 \mu \mathrm{mol} / \mathrm{l}$ okadaic acid (OKA), or $1 \mu \mathrm{mol} / 1$ calyculin A (CALY). After $30 \mathrm{~min}$ the incubations were terminated and samples of extracts were subjected to SDS-PAGE. Relative amounts of the different electrophoretic forms of PHAS-I were determined by optical density scanning. The results for PHAS-I $\alpha$ (left) and $\gamma$ (right) are expressed as percentages of the total PHAS-I and are from a representative experiment

\section{Discussion}

The results indicate that rapamycin and wortmannin decrease PHAS-I phosphorylation at concentrations just slightly higher than that required to inhibit the activation of $\mathrm{p} 70^{\mathrm{S} 6 \mathrm{~K}}$ by insulin (Figs. 2 and 3 ). Both wortmannin and rapamycin increased the amount of PHAS-I bound to eIF-4E (Fig. 4), indicating that the effects of the agents were functionally significant. Although not measured in the present study, increasing the amount of eIF-4E bound to PHAS-I would be expected to decrease the rate of translation initiation, thereby decreasing protein synthesis. It seems likely that the dephosphorylation of PHAS-I and the resulting inactivation of eIF-4E is involved in the effect of rapamycin on inhibiting translation initiation of mRNAs possessing the polypyrimidine motif near the $5^{\prime}$ cap site [6]. However, our results do not exclude the possibility suggested by Jefferies et al. [6] that dephosphorylation of ribosomal protein S6 is involved in this effect of rapamycin.

The intracellular receptor for rapamycin is FK506 binding protein-12 (FKBP12), a protein of $\mathrm{M}_{\mathrm{r}}$ equal to approximately 12000 [30-32]. The FKBP12- rapamycin complex binds tightly to a larger protein, designated TOR (target of rapamycin) that was first identified in yeast [30-32]. Both yeast and mammalian TOR (mTOR) proteins are homologous to PI 3 kinase [30-35]. Although it is not yet known if mTOR has lipid kinase activity, it is known that insulin activates PI 3 kinase and that wortmannin is a potent inhibitor of PI 3 kinase [22, 29]. Therefore, the present finding that wortmannin attenuates the effects of insulin on PHAS-I phosphorylation supports the hypothesis that PI 3 kinase activation can lead to phosphorylation of PHAS-I.

It seems clear that MAP kinase is not involved in the effect of rapamycin on PHAS-I as rapamycin promoted dephosphorylation of PHAS-I under conditions in which the effect of insulin on activating the ERK-1 and ERK-2 isoforms of MAP kinase was not inhibited [12]. There is increasing evidence to place $\mathrm{p} 70^{\mathrm{S} 6 \mathrm{~K}}$ downstream of PI 3 kinase and/or mTor in a pathway that is distinct from the MAP kinase signalling pathway. Both rapamycin and wortmannin block activation of $\mathrm{p} 70^{\mathrm{S} 6 \mathrm{~K}}$ by insulin and growth factors $[22,23,29,36,37]$. The finding that both agents attenuated the effects of insulin on increasing PHAS-I phosphorylation (Figs. 1 and 2) supports the hypothesis that the $\mathrm{p} 70^{\mathrm{S} 6 \mathrm{~K}}$ pathway is involved in controlling the phosphorylation of PHAS-I. p70 ${ }^{\mathrm{S} 6 \mathrm{~K}}$ does not appear to directly phosphorylate PHAS-I [21], but other elements in the pathway are candidates. One possibility is that the same kinase is responsible for phosphorylating both $\mathrm{p} 70^{\mathrm{S} 6 \mathrm{~K}}$ and PHAS-I. p70 6 S6K must be phosphorylated in several sites for full activation [38]. As inhibition of any one of several sites would prevent activation, partial inhibition of an activating kinase would be expected to have a more dramatic effect on the activity of $\mathrm{p} 70^{\mathrm{S} 6 \mathrm{~K}}$ than on the net phosphate content of $\mathrm{p} 70^{\mathrm{s} 6 \mathrm{~K}}$. Therefore, the finding that slightly higher concentrations of rapamycin and wortmannin were required to promote dephosphorylation of PHAS-I (Fig. 2) than to block activation of ribosomal protein S6 kinase (Fig. 3) is not inconsistent with the hypothesis that the agents inhibit a kinase that phosphorylates both PHAS-I and $\mathrm{p} 70^{\mathrm{S} 6 \mathrm{~K}}$.

Another possibility is that rapamycin and wortmannin promote dephosphorylation of PHAS-I by stimulating a phosphatase. Activation of a phosphatase has been suggested as a mechanism for the regulation of $\mathrm{p} 70^{\mathrm{S} 6 \mathrm{~K}}$, as rapamycin caused dephosphorylation of sites in $\mathrm{p} 70^{\mathrm{S} 6 \mathrm{~K}}$ distinct from those phosphorylated in response to mitogens [37]. The two major protein seryl/threonyl phosphatases in cells, Type I and IIA, are inhibited by okadaic acid and calyculin A [26]. Approximately 100 times higher concentrations of okadaic acid are required to inhibit Type I phosphatases than are needed to inhibit Type IIA phosphatases; whereas, these phosphatases are equally sensitive to inhibition by calyculin A [26] Thus, the finding that calyculin A was approximately 100 times more potent than okadaic acid with respect to increasing phosphorylation of PHAS-I (Fig.6) suggests that inhibition of Type I protein phosphatase is involved. However, additional evidence will be needed before reaching this conclusion, as calyculin A may cross membranes more readily than okadaic acid. Nevertheless, it is significant that neither phosphatase inhibitor abolished the effect of rapamycin (Fig.7). Therefore, if rapamycin acts by increasing PHAS-I phosphatase activity, then the 
rapamycin-sensitive phosphatase is not fully inhibited by either okadaic acid or calyculin A.

There is reason to believe that PHAS-I functions not only in the control of protein synthesis but also in the control of cell division. Increasing eIF-4E in cells has potent mitogenic actions [39] and has even been shown to promote malignant transformation of rodent fibroblasts [40], perhaps by increasing translation of messages encoding cellular oncogenes. Regardless of the mechanism, to the extent that eIF-4E is involved in the control of mitogenesis, PHAS-I is also implicated as it is a regulator of eIF-4E. The phosphorylation of PHAS-I and release of eIF-4E are stimulated by several mitogens, including insulinlike growth factor-1, platelet-derived growth factor $\mathrm{BB}$, and epidermal growth factor [11, 41]. As suggested previously $[11,12]$, the dephosphorylation of PHAS-I produced by rapamycin could be involved in the antiproliferative effects of the agent. In the context of the present experiments, it is interesting to note that the protein phosphatase inhibitor, okadaic acid, which promotes phosphorylation of PHAS-I (Figs. 5-7), was first characterized as a tumour promoter [42].

A cknowledgements. This work was supported in part by National Institutes of Health Grants RO1 DK28312-15 and AR41180.

\section{References}

1. Kimball SR, Vary TC, Jefferson LS (1994) Regulation of protein synthesis by insulin. Ann Rev Physiol 56: 321-348

2. O'Brien RM, Granner DK (1991) Regulation of gene expression by insulin. Biochem J 278: 609-619

3. DePhilip RM, Rudert WA, Lieberman I (1980) Preferential stimulation of ribosomal protein synthesis by insulin and in the absence of ribosomal and messenger ribonucleic acid formation. Biochemistry 19: 1662-1669

4. Hammond ML, Bowman LH (1988) Insulin stimulates the translation of ribosomal proteins and the transcription of rDNA in mouse myoblasts. J Biol Chem 263: 17785-17791

5. Manzella JM, Rychlik W, Rhoads RE, Hershey JW, Blackshear PJ (1991) Insulin induction of ornithine decarboxylase. J Biol Chem 266: 2383-2389

6. Jefferies HBJ, Reinhard C, Kozma SC, Thomas G (1994) Rapamycin selectively represses translation of the "polypyrimidine tract" mRNA family. Proc Natl Acad Sci USA 91: 4441-4445

7. Proud CG (1992) Protein phosphorylation in translational control. Curr Top Cellul Regul 32: 243-369

8. Avruch J, Alexander MC, Palmer JL et al. (1982) Role of insulin-stimulated protein phosphorylation in insulin action. Federation Proc 41: 2629-2633

9. Denton RM, Brownsey RW, Belsham GJ (1981) A partial view of the mechanism of insulin action. Diabetologia 21: 347-362

10. Hu C, Pang S, Kong X, Velleca M, Lawrence JC, Jr (1994) Molecular cloning and tissue distribution of PHAS-I, an intracellular target for insulin and growth factors. Proc Natl Acad Sci USA 91: 3730-3734
11. Graves LM, Bornfeldt KE, Argast GM, Krebs EG, Kong X, Lin T-A, Lawrence JC, Jr (1995) cAMP- and rapamycin-sensitive regulation of the association of eukaryotic initiation factor $4 \mathrm{E}$ and the translational regulator, PHAS-I, in aortic smooth muscle cells. Proc Nat Acad Sci U S A 92: 7222-7226

12. Lin T-A, Kong X, Saltiel AR, Blackshear PJ, Lawrence JC, Jr (1995) Control of PHAS-I by insulin in 3T3-L1 adipocytes: synthesis, degradation, and phosphorylation by a rapamycin-sensitive and MAP kinase-independent pathway. J Biol Chem 270: 18531-18538

13. Lin T-A, Kong X, Haystead TAJ, Pause A, Belsham GJ, Sonenberg N, Lawrence JC, Jr (1994) PHAS-I as a link between the MAP kinase and translation initiation. Science 266: 653-656

14. Pause A, Belsham GJ, Gingras AC, Donze O, Lin T-A, Lawrence JC, Jr., Sonenberg N (1994) Insulin-dependent stimulation of protein synthesis by phosphorylation of a regulator of 5' cap function. Nature 371: 762-767

15. Frederickson RM, Sonenberg N (1992) Signal transduction and regulation of translation initiation. Seminar in Cell Biol 3: 107-115

16. Hershey JWB (1991) Translational control in mammalian cells. Ann Rev Biochem 60: 717-755

17. Rhoads RE (1991) Protein synthesis, cell growth and oncogenesis. Current Opinion in Cell Biology 3: 1019-1024

18. Shatkin AJ (1987) mRNA caps-old and newer hats. Bioessays 7: 275-277

19. Lawrence JC, Jr, Lin T-A, Kong X, Haystead TAJ, Hu C (1995) PHAS-I: A new player in the regulation of protein synthesis by insulin and growth factors. In: Baba S, Kaneko $\mathrm{T}$ (eds) Diabetes 1994. Elsevier Science, Amsterdam pp 622-629

20. Gallie DR, Traugh JA (1994) Serum and insulin regulate cap function in 3T3-L1 cells. J Biol Chem 269: 7174-7179

21. Haystead TAJ, Haystead CMM, Hu C, Lin T-A, Lawrence JC, Jr (1994) Phosphorylation of PHAS-I by mitogen-activated protein (MAP) kinase. Identification of a site phosphorylated by MAP kinase in vitro and in response to insulin in adipocytes. J Biol Chem 269: 23185-23191

22. Chung J, Grammer TC, Lemon KP, Kazlauskas A, Blenis J (1994) PDGF- and insulin-dependent $\mathrm{pp} 70^{\mathrm{S} 6 \mathrm{k}}$ activation mediated by phosphatidylinositol-3-OH kinase. Nature 370: 71-75

23. Fingar DC, Hausdorff SF, Blenis J, Birnbaum MJ (1993) Dissociation of pp70 ribosomal protein S6 kinase from insulin-stimulated glucose transport in 3T3-L1 adipocytes. J Biol Chem 268: 3005-3008

24. Price DJ, Grove JR, Calvo V, Avruch J, Bierer BE (1992) Rapamycin-induced inhibition of the 70-kilodalton S6 protein kinase. Science 257: 973-977

25. Robinson LJ, Razzack ZF, Lawrence JC, Jr., James DE (1993) Mitogen-activated protein kinase activation is not sufficient for stimulation of glucose transport or glycogen synthase in 3T3-L1 adipocytes. J Biol Chem 268: 26422-26427

26. Cohen P (1991) Classification of protein-serine/threonine phosphatases: identification and quantitation in cell extracts. Methods Enzymol 201: 389-398

27. Smith PK, Krohn RI, Hermanson GT et al. (1985) Measurement of protein using bicinchoninic acid. Anal Biochem 150: 76-85

28. Laemmli UK (1970) Cleavage of structural proteins during the assembly of the head of bacteriophage T4. Nature Lond 227: 680-685

29. Cheatham B, Vlahos CJ, Cheatham L, Wang L, Blenis J, Kahn CR (1994) Phosphatidylinositol 3-kinase activation is required for insulin stimulation of pp70 S6 kinase, DNA 
synthesis, and glucose transporter translocation. Molec Cell Biol 14: 4902-4911

30. Schreiber SL (1991) Chemistry and biology of the immunophilins and their immunosuppressive ligands. Science 251: 283-287

31. Kunz J, Hall MN (1993) Cyclosporin A, FK506 and rapamycin: more than just immunosuppression. Trends Biochem Sci 18: 334-338

32. Clardy J (1995) The chemistry of signal transduction. Proc Natl Acad Sci USA 92: 56-61

33. Brown EJ, Albers MW, Shin TB et al. (1994) A mammalian protein targeted by G1 arresting rapamycin-receptor complex. Nature 369: 756-758

34. Sabatini DM, Erdjument-Bromage H, Lui M, Tempst P, Snyder SH (1994) RAFT1: a mammalian protein that binds to FKBP12 in a rapamycin-dependent fashion and is homologous to yeast TORs. Cell 78: 35-43

35. Sabers CJ, Martin MM, Brunn GJ et al.(1995) Isolation of a protein target of the FKBP12-rapamycin complex in mammalian cells. J Biol Chem 270: 815-822

36. Chung J, Kuo CJ, Crabtree GR, Blenis J (1992) Rapamycin-FKBP specifically blocks growth-dependent activation of and signaling by the $70 \mathrm{kd}$ S6 protein kinases. Cell 69: 1227-1236
37. Ferrari S, Pearson RB, Siegmann M, Kozma SC, Thomas G (1993) The immunosuppressant rapamycin induces inactivation of $\mathrm{p} 70^{\mathrm{s} 6 \mathrm{k}}$ through dephosphorylation of a novel set of sites. J Biol Chem 268: 16091-16094

38. Ferrari S, Bannwarth W, Morley SJ, Totty NF, Thomas G (1992) Activation of $\mathrm{p} 70^{\mathrm{s} 6 \mathrm{k}}$ is associated with phosphorylation of four clustered sites displaying Ser/Thr-Pro motifs. Proc Natl Acad Sci U S A 89: 7282-7286

39. De Benedetti A, Rhoads RE (1990) Overexpression of eukaryotic protein synthesis initiation factor 4E in HeLa cells results in aberrant growth and morphology. Proc Natl Acad Sci USA 87: 8212-8216

40. Lazaris-Karatzas A, Montine KS, Sonenberg N (1990) Malignant transformation by a eukaryotic initiation factor subunit that binds to mRNA 5 ' cap. Nature 345: 544-547

41. Blackshear PJ, Nemenoff RA, Avruch J (1983) Insulin and growth factors stimulate the phosphorylation of a $\mathrm{Mr}_{\mathrm{r}^{-}}$ 22,000 protein in 3T3-L1 adipocytes. Biochem J 214: 11-19

42. Cohen P, Holmes CF, Tsukitani Y (1990) Okadaic acid: a new probe for the study of cellular regulation. Trends Biochem Sci 15: 98-102 